\title{
Design discussion of Foundation Reinforcement for A School Canteen Building
}

\author{
Ma Xiuping* \\ Shandong Urban Construction Vocational College, Jinan, China
}

\begin{abstract}
This paper took a RC frame building as example whose foundation need to be reinforced for translation and storey addition. Three reinforcement design schemes are raised. Scheme I: Integral foundation consolidation. Scheme II: Restructuring the original foundation into rigid foundation with additional longitudinal strip foundation. Scheme III: Adopting anchor isostatic pressing piles as foundation consolidation. Scheme II should be the chosen one after comparison.
\end{abstract}

\section{INTRODUCTION}

The School Canteen is a RC frame building with two overground floors and one underground floor. The plane size of the building is $24 \mathrm{~m} \times 59 \mathrm{~m}$. The height of the underground floor is $3.2 \mathrm{~m}$ while that of the first overground floor is $6.0 \mathrm{~m}$ and the second $4.25 \mathrm{~m}$. The pillar space is $8 \mathrm{~m} \times 8 \mathrm{~m}$. It is of transverse strip foundation with the bottom elevation being $4.800 \mathrm{~m}$. The concrete strength grades of the underground part and the overground part are C30 and C25 respectively. The bearing stratum of foundation is loess silty clay, whose characteristic bearing capacity is $130 \mathrm{~K}$. The building construction was completed and came into service in 2003. However, this canteen would be translated $50 \mathrm{~m}$ northward due to an adjustment of the comprehensive planning. Nevertheless two more floors were designed to be built out on the basis of the original building. Consequently and naturally the foundation need to be reinforced. The plan and elevation of the building is shown in Fig.1.

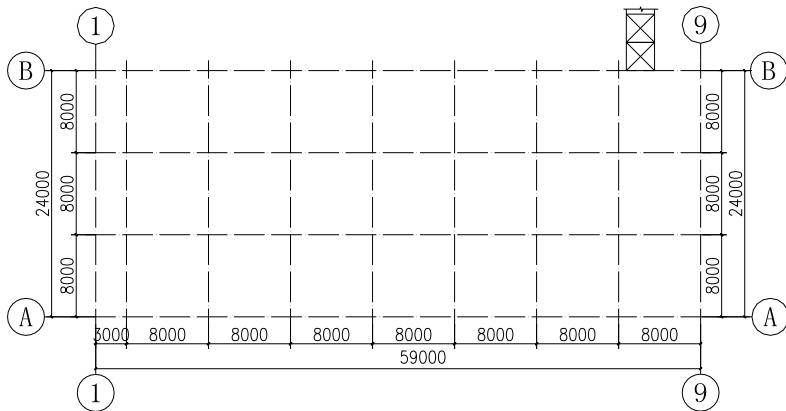

Plan of the building

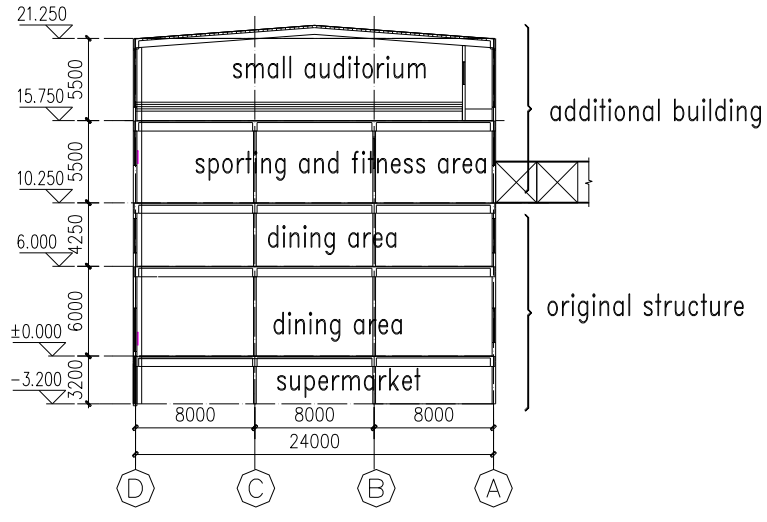

Elevation of the building

Fig.1 Original Structure and additional building

\section{STRUCTURE OVERVIEW}

The original foundation is transverse strip foundation whose beam section is $0.9 \mathrm{~m} \times 1.45 \mathrm{~m}$, bottom width being $4 \mathrm{~m}$. The distance between the indoor floor and foundation bottom is $2 \mathrm{~m}$. After translation, the height of foundation beam would increase $1.15 \mathrm{~m}$ and the elevation of the bottom raised by $0.3 \mathrm{~m}$ while the bottom width remains unchanged. Those frame columns would be connected and fixed with the new foundation after translation. ${ }^{11}$ The changes before and after translation are shown in table 1.

\subsection{Low reinforcement of foundation bottom}

The original reinforcement of foundation bottom before translation is $\$ 16 @ 120$. After translation, it turns to be \$16@140, seeing a 14\% reduction. 


\subsection{Low reinforcement of foundation beam}

The original reinforcement of foundation beam before translation is $12 \Phi 25$ at the top of the foundation beam and $18 \Phi 25$ at the bottom of the foundation beam with a $1.45 \mathrm{~m}$ foundation height. After translation, the reinforcement of foundation beam is $10 \$ 25$ at the top of the foundation beam and $14 \Phi 18$ at the bottom of the foundation beam with a $1.15 \mathrm{~m}$ foundation height. In the original foundation beam, the steel bars did not stretch into the supports as anchoring. Instead, reinforced haunch of triangular plain concrete is poured on both sides of the support whose size is $0.35 \mathrm{~m} \times 1.15 \mathrm{~m}$. However, without steel bars, the haunching would contribute little to anchoring.

\subsection{Unembedded Frame Columns}

Originally, the foundation and columns are poured integrally. The steel bars within columns are stretched into the foundation bottom and embedded. After translation, newly built foundation did not have pre-buried joint bars to connect with frame columns. On the contrary, the steel bars are embedded into the foundation beam and columns firstly and respectively then connected. As a result, the connection helps little in reinforcing those frame columns.

Tab.1 comparison before and after translation

\begin{tabular}{|c|c|c|c|}
\hline & before & after & comparison \\
\hline $\begin{array}{c}\text { foundation } \\
\text { dimension }\end{array}$ & $\begin{array}{c}0.9 \mathrm{~m} \times 1.45 \mathrm{~m} \\
\times 4 \mathrm{~m}\end{array}$ & $\begin{array}{c}0.9 \mathrm{~m} \times 1.15 \mathrm{~m} \\
\times 4 \mathrm{~m}\end{array}$ & raise $0.3 \mathrm{~m}$ \\
\hline $\begin{array}{c}\text { reinforce- } \\
\text { ment of } \\
\text { foundation } \\
\text { slab }\end{array}$ & $\Phi 16 @ 120$ & $\Phi 16 @ 140$ & reduce $14 \%$ \\
\hline
\end{tabular}

\begin{tabular}{|c|c|c|c|}
\hline $\begin{array}{c}\text { reinforce- } \\
\text { ment of } \\
\text { foundation } \\
\text { beam }\end{array}$ & $\begin{array}{c}\text { top } 12 \Phi 25 \\
\text { bot- } \\
\text { tom } 18 \Phi 25\end{array}$ & $\begin{array}{c}\text { top } 10 \Phi 25 \\
\text { bot- } \\
\text { tom14 } \Phi 18\end{array}$ & reduce $17 \%$ \\
\hline $\begin{array}{c}\text { the embed- } \\
\text { ded problem } \\
\text { of column }\end{array}$ & $\begin{array}{c}\text { poured inte- } \\
\text { grally }\end{array}$ & $\begin{array}{c}\text { not poured as } \\
\text { a whole }\end{array}$ & $\begin{array}{c}\text { structural } \\
\text { measures }\end{array}$ \\
\hline
\end{tabular}

\section{DESIGN SCHEMES OF FOUNDATION REINFORCEMENT ${ }^{[2]}$}

Three reinforcement design schemes are raised. Scheme I: Adding longitudinal foundation beam, horizontal foundation beam with joist foundation package and fixation of frame columns as an integral consolidation. Scheme II: Restructuring the original foundation into rigid foundation with additional longitudinal strip foundation. Scheme III: Adopting anchor isostatic pressing piles as foundation consolidation. ${ }^{[4]}$ These three design schemes will be introduced respectively as follows.

\subsection{Integral foundation consolidation}

Scheme I involved adding longitudinal foundation beam and horizontal foundation beam with joist. The steel bars at the column base would be connected with the foundation beam to form a united whole (see Fig. 2).

\subsubsection{Additional Longitudinal foundation beam}

For that the reinforcement of the original horizontal foundation beam is inadequate, 30 percent of the whole load is allocated to it while the rest 70

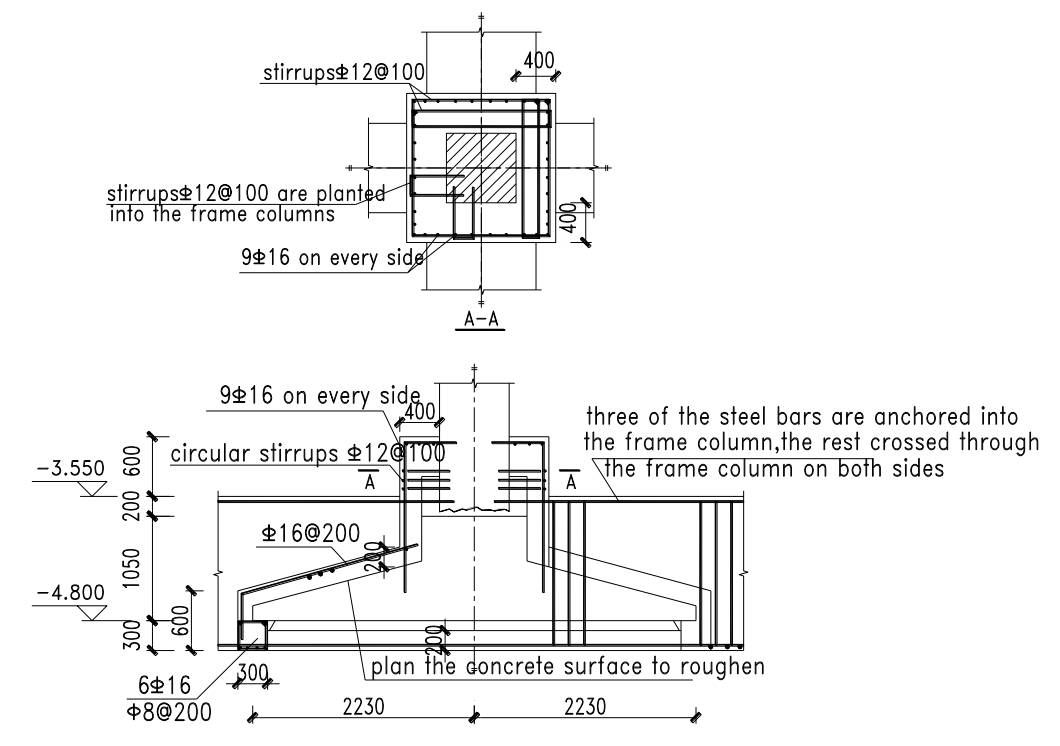

Fig.2 The Foundation, foundation beam reinforcement and embedded frame columns 
percent load would be bore by the additional longitudinal foundation beam. Through the calculation, the width of the newly added longitudinal foundation beam is $0.9 \mathrm{~m}$ with a $1.45 \mathrm{~m}$ foundation beam height. Three steel bars in the middle of the foundation beam are anchored into the frame columns. The rest of those steel bars crossed through the supports on both sides. Those steel bars are designed in two rows so that the number of parallel embedded steel bars could be decreased to some degree. A $200 \mathrm{~mm}$ high hole is excavated in the bottom part of the horizontal foundation, through which the steel bars crossed. The holes are sealed off by pressure grouting of micro-expanding.

\subsubsection{Horizontal foundation beam with joist}

For the inadequate reinforcement of the original horizontal foundation bottom, this scheme is designed as a remedy by adopting extended horizontal foundation bottom with joist and reallocating the stress on bottom steel bars. The size of joist cross section is $0.3 \mathrm{~m} \times 0.3 \mathrm{~m}$ with a length of $4 \mathrm{~m}$. The reinforcement of the joist is $6 \Phi 16$, poured together with the longitudinal foundation. The foundation bottom is thickened by $200 \mathrm{~mm}$ with the reinforcement of $\Phi 14 @ 200$. Those steel bars are planted into the socket foundation to increase the load capacity after translation.

\subsubsection{Embedded frame columns}

Owing to that the embedding frame columns into the foundation could not meet the anchoring requirements, reinforced concrete socket foundation around the frame columns are poured, whose height and thickness are $800 \mathrm{~mm}$ and $400 \mathrm{~mm}$ respectively. The reinforcement of the socket foundation is $9 \Phi 16$ on both sides, and it is connected with the foundation beam and bottom by steel bars. The socket foundation would be connected around the columns by steel bars thus the embedding consolidation of the frame columns could be achieved.

\subsection{Adding longitudinal strip foundation to rigid foundation}

The insufficient reinforcement of the foundation and foundation beam would hinder it from bearing the load after reconstruction. Scheme II could form an independent rigid foundation by heightening it, thus solving the reinforcement inadequacy problem. Besides, the concrete can also reinforce frame columns in the meantime (see Fig. 3). The reinforcement around the independent rigid foundation is $\Phi 16 @ 150$ with bidirectional structural steel fabrics who can be welded with the steel bars or the embedded steel bars in the horizontal foundation to form a united whole.

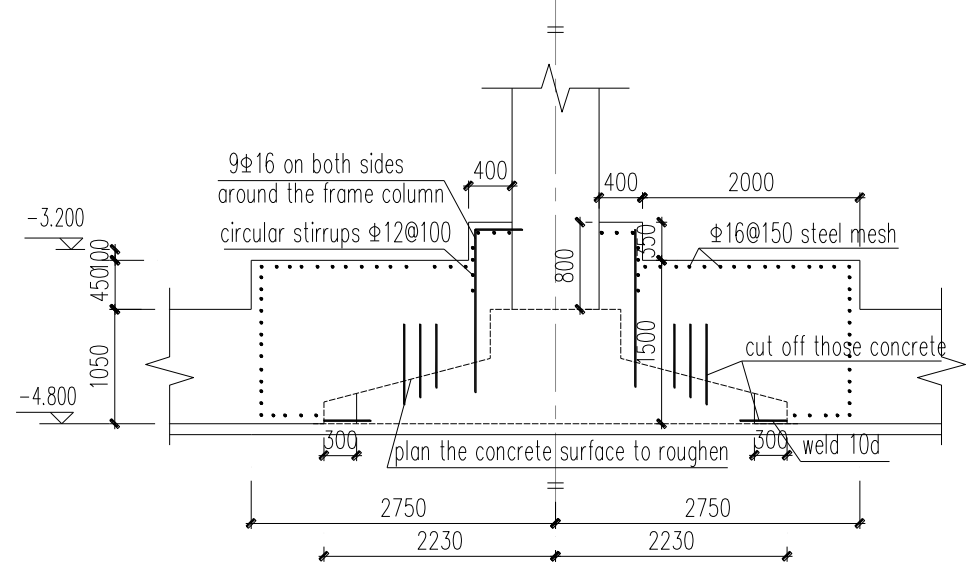

Fig.3 Rigid foundation

The longitudinal strip foundation is added with both sides bolted into the rigid foundation. Cooperating with the original lateral foundation, it will to a great extent enhance the foundation bearing capacity.

\subsection{Static bolt-pile consolidation ${ }^{[5]}$}

Scheme III is to take the original foundation as a base, which would be drilled. The precast piles would be pressed into soil by using through the equipment of anchor-arm static-pressure pile with concrete poured on the foundation to fix the pile heads and to embed the frame columns. Piles and soil share the upper load, which, as a result of checking calculation, could satisfy the requirements of foundation bearing capacity (see Fig. 4).

$$
\text { Reinforced concrete piles (C30 size: }
$$
$200 \mathrm{~mm} \times 200 \mathrm{~mm})$ are adopted. The minimum reinforcement ratio is 1.0 percent. Micro-expanding early strength concrete $\mathrm{C} 30$ is poured to seal it, before which the drill holes would be cleaned up with pile heads cut off and scabbled. 


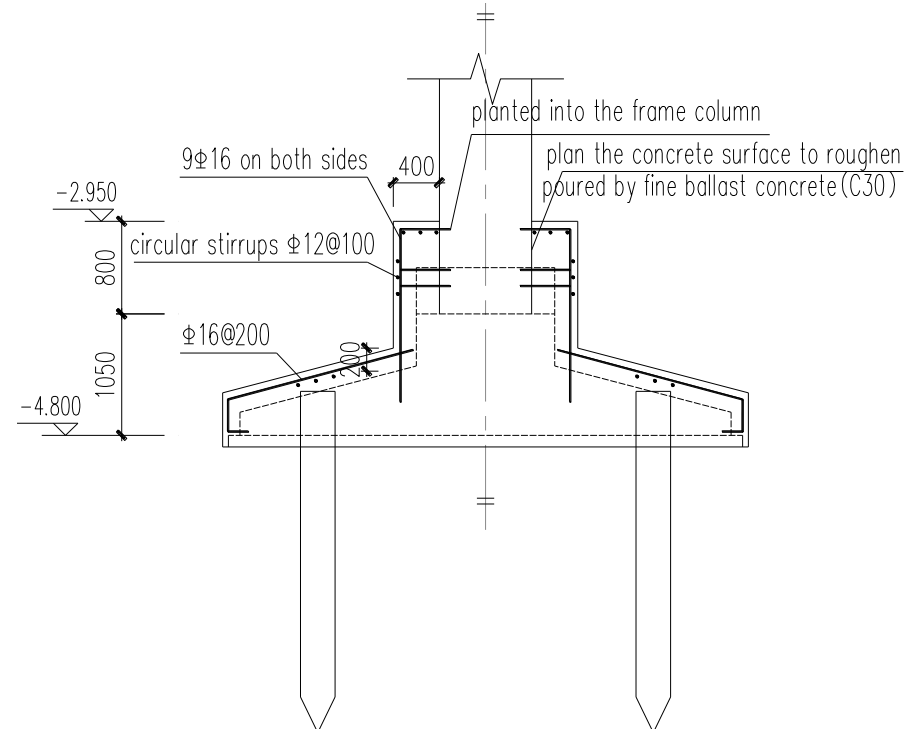

Fig.4 Static bolt-pile consolidation

\section{SUMMARY}

All of three reinforcement design schemes could solve the problem of inadequate foundation bearing capacity and frame column embedding brought up by the translation and reconstruction. Scheme I need excavating a hole in the below of the horizontal foundation which is of much difficulty and bears a comparatively long period.
Therefore, the operation quality is hard to guarantee even it costs much. Scheme III needs much room for the machine operation, which is not easy to realize as the height of the basement is less than $2 \mathrm{~m}$. Scheme II should be the chosen one as it bears easy operation, low costs and short period. The advantages and disadvantages of the three schemes are shown in Table 2.

Tab.2 comparison of reinforcement schemes

\begin{tabular}{|c|c|c|c|}
\hline & Scheme I & Scheme II & Scheme III \\
\hline advantage & \multicolumn{2}{|c|}{ enough bearing capacity, slove the embedded problem of column } \\
\hline shortcoming & $\begin{array}{c}\text { difficult construction, long } \\
\text { construction period }\end{array}$ & $\begin{array}{c}\text { easy operation, low } \\
\text { costs }\end{array}$ & $\begin{array}{c}\text { small operation } \\
\text { platform, high costs }\end{array}$ \\
\hline choice & not good & good & not good \\
\hline
\end{tabular}

In the design of multi-layer structures, comparisons should be conducted among a variety of schemes before making the final choice. Nevertheless, the soft soil foundation must be considered and properly managed to avoid the differential settlement of foundation caused by load variation or other factors.

\section{REFERENCES}

1. Ministry of Construction, PRC. GB 50367-2013 Design code for strengthening concrete structure. Beijing: China Architecture \& Building Press (2013).

5. Zhu Lianyong, Ren Yaping and Li Yanhe: Study on Selection of Foundation Reinforcement in Rebuilding Engineerings, Building Structure, 2006(6): 9395 .
2. Ministry of Construction, PRC. JGJ 116-2009 Technical specification for seismic strengthening of buildings. Beijing: China Architecture \& Building Press (2009).

3. Ministry of Construction, PRC. GB 50007-2011 Code for design of building foundation. Beijing: China Architecture \& Building Press (2011).

4. Chen Aixin. and Liu Changqing: Geotechnical investigation for strengthening and remedy of the existing building foundation and scheme options for foundation reinforcement Reference,. Geotechnicallnvestigation \& Surveying, 2010(4): 27-30. 